\title{
ETNOBOTÂNICA: ASPECTOS HISTÓRICOS E APLICATIVOS DESTA CIÊNCIA
}

\author{
Fabio Franco $^{1}$; Ana Paula do N. Lamano-Ferreira ${ }^{1,2}$; Maurício Lamano Ferreira ${ }^{1,3}$
}

\section{Resumo}

As plantas medicinais representam uma importante ferramenta na promoção da saúde e cultura em muitas regiões do Brasil e em particular para muitas comunidades que detém esse tipo de conhecimento, sendo assim de grande interesse na etnobotânica e na etnofarmacobotânica. Este trabalho teve como objetivo realizar um levantamento bibliográfico sobre alguns aspectos culturais, religiosos e alimentícios da etnobotânica. Para alcançar este propósito foram feitas pesquisas em artigos científicos e em livros. No levantamento bibliográfico observou-se que a etnobotânica apresenta diferentes vertentes em suas aplicações, sendo a etnofarmacobotânica ganha destaque especial em comunidades tradicionais. A etnobotânica investiga e estuda o uso de plantas com fins medicinais, culturais, religiosos e conservacionistas, oferecendo assim elementos práticos para investigadores e favorecendo a descoberta de novos medicamentos. O estudo de etnobotânica ainda se encontra pouco difundido no país, sendo que a área apresenta alto potencial de estudo.

Palavras chave: plantas medicinais; conhecimento empírico; plantas alimentícias

\section{ETHNOBOTANY: HISTORICAL ASPECTS AND APPLICATIONS OF THIS SCIENCE}

\begin{abstract}
Medicinal plants represent an important tool in promoting health and culture in many regions of Brazil and in particular for many communities that has this kind of knowledge, thus being of great interest in ethnobotany and ethnopharmacobotany. This study aimed to conduct a literature review on some aspects of cultural, religious and food of ethnobotany. To achieve this goal it has been made a research in scientific papers and books. In the literature it was observed that the ethnobotany presents different aspects in their applications, and the etnofarmacobotânica gets special attention in traditional communities. The ethnobotany and study investigates the use of plants for medicinal, cultural, religious and conservationists, providing practical information for researchers and encouraging the discovery of new drugs. The study of ethnobotany is still not widespread in the country, and the area has high potential to study.
\end{abstract}

Key words: medicinal plants; empirical knowledge; food plants

\footnotetext{
1 Bacharel em Ciências Biológicas na Universidade Nove de Julho, São Paulo, SP, Brasil,

2 Profa. Dra. em Ecologia na Universidade Nove de Julho e pós doutoranda na ESALQ/USP, Piracicaba/SP.

3 Prof. Msc. de Botânica e Ecologia na Universidade Nove de Julho e doutorando no Centro de Energia Nuclear na Agricultura (CENA-USP), Piracicaba/SP
} 


\section{Introdução}

A população humana tem se relacionado intimamente com o cultivo de plantas desde as suas primeiras organizações sociais, quando os quintais passaram a ser uma estratégia de cultivo do seu próprio alimento e remédios. O uso popular de plantas é uma arte muito antiga fundamentada no acúmulo de informações repassadas oralmente através de sucessivas gerações (NASCIMENTO, 2008).

Uma importante subárea da botânica, a etnobotânica, tem ganhado destaque na área científica devido à grande conexão que se estabelece entre conhecimento popular e ciência propriamente dita.

A etnobotânica é uma ferramenta relativamente barata de pesquisa que favorece a relação do homem com a vasta diversidade vegetal, que por sua vez, contribui de forma significativa nas enfermidades humanas, nos rituais religiosos e até mesmo em padrões de alimentação.

Para Prance (1991), somente a partir dos trabalhos de Carl Linnaeus que se inicia a história da etnobotânica, porque seus diários de viagens continham dados referentes às culturas visitadas, os costumes de seus habitantes e o modo de utilização das plantas.

Para Albuquerque e Lucena (2004), a etnobotânica não possui uma estrutura conceitual estabelecida que defina seus métodos, entretanto, ela se sustenta em conceitos antropológicos, botânicos e ecológicos.

A experiência de muitos pesquisadores tem favorecido métodos compatíveis com a abordagem etnocientífica, uma vez que a definição dos métodos de qualquer ciência depende das concepções teóricas defendidas por esta ciência. Dentre tais métodos se podem destacar o uso tradicional e amplo das plantas para tratamentos de certas doenças. (PHILLIPS; GENTRY 1993).

Podem-se encontrar estudos etnobotânicos relativamente antigos, pois com a proximidade a novos povos detentores de tais conhecimentos alguns cientistas mostraram interesse pelo assunto, como foi o caso Carl Friedrich Philipp von Martius e Joahnn Baptist Ritter von Spix no século XIX, que fizeram notas do uso de plantas por indígenas brasileiros.

Já muito antes (no século XVII), no Nordeste do Brasil, os holandeses Guilherme Piso e Georg Marggraf, coletaram plantas e registraram usos conhecidos pelos nordestinos. (ALBUQUERQUE, 2002).
Diversos estudos etnobotânicos vêm sendo desenvolvidos no Brasil e no mundo buscando conhecer a medicina e rituais dos diversos povos étnicos. Devem-se ressaltar estudos em comunidades indígenas, tais como o desenvolvido por Rodrigues (2001), que trabalhou com um comunidade indígena da etnia Krahô, Coutinho e colaboradores (2002), que realizaram estudo etnobotânico de plantas medicinais utilizados por comunidades indígenas no estado do Maranhão e, Morais e colaboradores (2005) com o levantamento das plantas medicinais usadas pelos índios Tapebas do Ceará.

Todos evidenciaram a diversidade de espécies vegetais utilizadas como medicinais, proporcionando um maior conhecimento aplicado da flora.

O Brasil, um dos países de maior diversidade genética vegetal ocupa posição de destaque no que se diz respeito ao patrimônio vegetal genético nacional (NORDORI; GUERRA, 1999).

Dessa forma, atualmente, muitas plantas que nos rodeiam podem apresentar uma produção de substâncias químicas que podem atuar beneficamente sobre outros organismos ou agirem de forma tóxica. Para que o homem possa fazer uso de uma espécie, com segurança, é necessário que a mesma seja estudada do ponto de vista químico, farmacológico, toxicológico e etnológico, quando possível (RITTER et al. 2002).

Assim, este trabalho objetivou fazer um levantamento bibliográfico sobre a etnobotânica e suas aplicações.

\section{Método}

A pesquisa em questão constituiu-se num levantamento de publicações científicas relacionadas a etnobotânica. As bases de dados foram consultadas entre agosto de 2009 à outubro de 2010.

As palavras chaves foram cruzadas de três maneiras distintas: plantas medicinais; etnobotânica, conhecimento empírico. Apesar disto o estudo versa sobre uma revisão bibliográfica não sistematizada. Para análise e síntese do material realizou-se uma leitura exploratória do material bibliográfico.

Após isso houve uma leitura seletiva, determinando assim o material mais pertinente ao tema do trabalho. Por fim, procedeu-se a leitura analítica a fim de sumarizar e hierarquizar as informações contidas nos periódicos e livros consultados, possibilitando assim, a obtenção de resposta ao problema da pesquisa. 


\section{Resultados e Discussão}

No Brasil, o uso das plantas com fins medicinais foi disseminado principalmente pela cultura indígena. Os índios, assim como a população em geral, fazem uso de plantas medicinais no tratamento de suas doenças (VEIGA-JÚNIOR, 2008).

Nos artigos consultados as espécies herbáceas, cultivadas ou espontâneas, são as que apresentaram maior importância em estudos dessa natureza, porém, há de se considerar as plantas de hábito arbóreo, subarbustivo e arbustivo (CAVALCANTE; FRIKEL, 1973; RODRIGUES, 2001; COUTINHO; TRAVASSOS; AMARAL, 2002).

Há evidências de que a seleção de plantas para uso medicinal não é feita ao acaso e que famílias botânicas com compostos bioativos tendem a ser mais bem representadas nas farmacopéias populares (MOERMAN; ESTABROOK, 2003). No entanto, para Morais e colaboradores (2005), muitas espécies utilizadas ainda não existem em trabalhos científicos, fato que não garante seu uso seguro.

\section{Aspecto histórico}

O interesse dos povos e sociedades em relação ao meio ambiente, em especial aos vegetais, data de milhares de anos. Registros históricos demonstram que na antiguidade, o homem já conhecia diversas propriedades das plantas, dentre estas, as propriedades medicinais (FERNANDES, 1982).

Diversos estudos etnobotânicos vêm sendo desenvolvidos no Brasil buscando conhecer a medicina indígena e quilombola e a forma de organização desses conhecimentos, no entanto, temse observado que há poucas referências etnobotânicas para os povos indígenas do Brasil, que apesar de ser um país com uma grande diversidade cultural e biológica, estudos de natureza etnobotânica ainda não são representativos, quando comparados com estudos relacionados a outras áreas (ALBUQUERQUE, 2000).

Segundo Albuquerque, (2002) Alphonse De Candolle publicou em 1886, "A origem das plantas cultivadas", onde dados etnobotânicos foram utilizados nos estudos sobre a origem de plantas cultivadas. Já o termo etnobotânica foi designado em 1895 pelo americano John Willian Harshberger que apresentou uma definição pragmática para essa área do saber:

\section{"É considerado que a etnobotânica possa auxiliar no esclarecimento da cultura das etnias que utilizam as plantas de forma medicinal ou em rituais".}

Sobre este aspecto é importante dizer que homem foi e é o agente de mudanças de evolução vegetal doméstica, pois desde os primórdios da civilização humana o meio botânico esteve relacionado à sua sobrevivência, manipulando-a não somente para suprir suas necessidades nutritivas, mas também culturais e farmacológicas.

Nos últimos anos surgiram importantes trabalhos sobre o assunto, porém ainda são raros os que são escritos em português, embora sejam encontrados alguns relatos na literatura brasileira. Este é o caso de Munanga (1996), que estudou comunidades indígenas e quilombolas.

Ele destaca em seu trabalho a origem destes povos bem como o uso de plantas em rituais e na medicina. $\mathrm{O}$ autor comenta que para se entender mais sobre as plantas, é preciso mergulhar um pouco em mitos e rituais populares, uma vez que a cultura, em geral, influencia a saúde e a forma de como lidar com o corpo.

\section{Aplicações e implicações da Etnobotânica}

Vários são os objetivos e justificativas que levam pesquisadores a desenvolver uma pesquisa etnobotânica. Existem, entretanto, tendências gerais que sugerem a realização destas pesquisas em um contexto.

Normalmente o objetivo de estudo de tais pesquisas são os chamados grupos culturalmente definidos que possuam nitidamente estreita relação com os recursos naturais e, portanto, um conhecimento histórico e/ou tradicionalmente acumulado. Muitas vezes a localização geográfica de isolamento ou semi-isolamento junto a ricas fontes de recursos naturais proporciona esta estreita relação, devido às dificuldades de acesso (físico e/ou econômico) aos insumos para sobrevivência, recorrendo aos recursos naturais (ALBUQUERQUE; LUCENA, 2004).

Os autores referidos anteriormente afirma que dentro de uma lógica das metas do estudo, estas pesquisas objetivam em geral: 


\begin{abstract}
"Resgatar o conhecimento tradicional de grupos definidos culturalmente, a respeito da manipulação de recursos vegetais e de recursos biologicamente ativos - etnobotânica $e$ etnofarmacologia, respectivamente, de modo a correlacionar a relação entre o homem $e$ o meio ambiente, particularmente os recursos naturais, com sua cultura peculiar, fazendo uma etnografia do grupo."

"Descobrir novos recursos ainda não explorados pela ciência e novas técnicas de manipulação e conservação destes e dos recursos já conhecidos, a fim de subsidiar mudanças de conceitos fundamentais da ciência clássica visando à melhoria da qualidade de vida global."
\end{abstract}

A justificativa desse tipo de pesquisa é, portanto, o resgate cultural visando desenvolver estratégias de conservação da biodiversidade e proteção da etnobiodiversidade, entretanto há um impasse difícil de ser solucionado nas pesquisas "etno", pois são na maioria das vezes fontes potenciais de lucro e benefícios para manipuladores dos dados da pesquisa e para a humanidade, tendo um grande valor de conhecimento dos grupos culturais, assim se revela um dos mais polêmicos desafios destas pesquisas, garantirem os direitos à propriedade intelectual (idéias, invenções e expressão criativa) desses grupos, pois há o desejo de se dar o status de propriedade a essas invenções e expressões das comunidades estudadas. Desde a década de 80 a chamada "década da ética", etnocientistas tem discutido esta questão, entretanto pouco de concreto tem evoluído no sentido de encaminha-lá. (SHERWOOD, 1992).

Além disso, uma planta com um índice de concordância relativamente alto, isto é, que possua diversas referências concordando com um mesmo uso terapêutico, talvez possa sugerir uma verdadeira efetividade no tratamento da doença, esse índice de referência facilitará a seleção de espécies para testes farmacológicos que possam vir a comprovar uma real eficácia de seus princípios ativos (FRIENDMAN et al, 1986).

Etnofarmacologia, Farmacognosia e Fitoterápicos
A etnofarmacologia é uma ciência que procura entender o universo dos recursos naturais (plantas, animais e minerais) utilizados como drogas sob a ótica de grupos humanos (RAO; HAJHARA, 1987).

Levantamentos etnofarmacológicos realizados em comunidades residentes próximo às matas brasileiras são instrumentos promissores, uma vez que o país possui altos índices de biodiversidade e endemismo associados a um processo de miscigenação intenso que resultou numa riqueza considerável de conhecimentos sobre a sua flora.

No Brasil, estes levantamentos têm focado os grupos indígenas (CAVALCANTE; FRIKEL, 1973) as populações tradicionais, tais como os caiçaras (BEGOSSI, 1993) e os caboclos, (MING, 1995), sendo o negro raramente incluído, com exceção dos trabalhos realizados por Camargo (1998) e recentemente por Albuquerque (2001).

$\mathrm{O}$ termo Farmacognosia, etimologicamente significa o conhecimento dos fármacos (gnose) ou venenos (pharmacon), é considerado o estudo de matérias-primas e substâncias de origem biológica, ou seja, obtidas a partir dos vegetais, animais ou fermentação a partir de microrganismos, com fins terapêuticos. É uma ciência aplicada, de caráter, necessariamente multidisciplinar.

Restringido ao estudo de drogas e substâncias de origem vegetal, a farmacognosia envolve o estudo da identificação de drogas vegetais por caráter morfológicos e anatômicos, o estudo de sua origem e formas de produção, de sua qualidade composição química, elucidação estrutural e conhecimento das propriedades físico-químicas das substâncias ativas, bem como suas propriedades farmacológicas e toxicológicas (BRUNETON, 1993).

Os fitoterapêuticos são medicamentos feitos de partes de plantas cujos princípios ativos não foram purificados, como chás, extratos e tinturas, podendo ser produtos de venda e de uso livre e, desta forma, estão diretamente ligados à automedicação (RATES; SANTOS, 1997).

O uso de fitoterápicos remonta aos tempos ancestrais e seu uso na medicina popular sempre foi bem difundido, porém, hoje em dia, há uma abordagem científica desses medicamentos com estudos clínicos para verificar a eficácia.

Muitas plantas medicinais bastante populares não tiveram sua eficácia comprovada e podem até ser tóxicas sendo comum a crença errônea de que os fitoterápicos, por serem provenientes de plantas, não acarretam riscos à saúde. Porém são medicamentos, e como tal podem ter efeitos colaterais em potencial e devem ser usado sob orientação médica. 
A interação dos medicamentos fitoterápicos com drogas sintéticas é uma grande preocupação da medicina atual, por isto, estes devem ser preparados de forma correta e utilizados em doses e horários definidos, pois como qualquer medicamento, as plantas também podem desencadear sérios efeitos colaterais (ZUCOLOTTO; APEL; RATES, 1999).

Segundo a Agência Nacional de Vigilância Sanitária (ANVISA), alguns fitoterápicos podem auxiliar no tratamento de várias doenças, por meio da Resolução RDC 89/2004 (BETTEGA et al., 2011), que publicaram uma lista de fitoterápicos de registro simplificado e buscou estabelecer a padronização de marcadores químicos para diversas plantas e limite diário para seu uso.

Entende-se esta preocupação como etapa fundamental para assegurar o uso e garantir eficácia ao fitoterápico. Buscando atuar neste contexto, a necessidade de determinar o teor de princípios ativos em matérias-primas vegetais, embora diversos estudos tenham demonstrado a necessidade de garantir segurança aos produtos de origem vegetal (POSEY, 1987).

\section{Realização de um trabalho etnobotânico}

Albuquerque (2002), menciona que na adequação da metodologia ao problema principal da pesquisa, deve se questionar qual o melhor meio de se analisar o problema enfocado na conclusão de qualquer investigação cientifica e na livre escolha que tem o pesquisador de usar os métodos compatíveis com os objetivos a serem alcançados, seja dando uma ênfase quantitativa ou qualitativa, ou a associação de ambas.

De posse de todo o arsenal teórico e prático necessário, devem ser considerados os aspectos de extrema relevância em uma pesquisa, as regras principais para a pesquisa etnobiológica e as considerações para o campo da investigação etnobotânica que são, segundo Posey (1987):

a) Estudar a botânica desenvolvida por outras culturas tendo em mente que estas se esforçam por classificar, catalogar e utilizar racionalmente o mundo vegetal, tratando os informantes como especialistas no assunto, uma vez que verdadeiramente são, pois dominam conhecimentos e fenômenos que nos são desconhecidos e que buscamos compreender.

b) Evitar perguntas etnocêntricas, ou seja, não colocar a visão do mundo onde o nosso próprio grupo é tomado como centro de tudo e nem impor suas próprias idéias. Participar sem alterar o curso normal das atividades e comportamento dos informantes.

c) Estabelecer contato amigável e receptivo com os informantes, deixando que os mesmos sejam os guias da pesquisa, não rejeitando dados ou informações que a primeira vista pareça insignificante ou absurda

Para Albuquerque e Lucena (2004), a observação participante, originada da Antropologia, é muito útil na abordagem etnobotânica, pois permite minimizar a influência de inventários superficiais instrumentalizados pela aplicação fria de formulários e questionários. Trata-se de um fator limitante à pesquisa facultando assim revelar detalhes não explicados durante as entrevistas formais, bem como acrescer nas listagens obtidas espécies não informadas fazendo assim, qualquer situação em que plantas e pessoas se vejam envolvidas pode ser apuradas em busca de sentido e lógica.

Apesar de toda a importância de um questionário em um trabalho desta natureza outro ponto que não pode ser deixado de lado é a escolha da planta a ser estudada a qual, pode ser feita de três formas: a) abordagem randômica - escolha da planta sem qualquer critério, tendo como fator determinante a disponibilidade da planta; b) abordagem quimiotaxonômica ou filogenética - seleção da espécie correlacionada com a ocorrência de uma dada classe química de substâncias em um gênero ou família; c) abordagem etnofarmacológica - seleção da espécie de acordo com o uso terapêutico evidenciado por um determinado grupo étnico (MACIEL, 2002).

A aplicação da etnobotânica dentro de uma dinâmica própria em que se desenvolve a relação pessoas/plantas possui ainda uma multiplicidade de questões e níveis interativos que a circundam, indo além da descrição ou qualificação de uma planta e a devolução desse conhecimento as comunidades, como nos trabalhos de Rodrigues (2001), Coutinho e colaboradores (2002), Morais e colaboradores (2005).

Basta constatarmos a carta de Belém elaborada durante o Congresso Internacional de Etnobiologia, ocorrido em 1988 em Belém-Pará, que muitos ecossistemas frágeis estão desaparecendo e com isso espécies vegetais com potencial medicinal pra muitos males estão se extinguindo sem ao menos serem conhecidos (ALBUQUERQUE, 2005).

As pesquisas etnobotânicas realizadas no decorrer dos últimos 100 anos têm provado essa afirmativa, evidenciando com um discurso científico e conduzindo a uma direção na qual se possa tomar 
medidas concretas com mecanismos práticos que vissem sanar esse problema.

\section{Considerações Finais}

As pesquisas com plantas medicinais envolvem investigações da medicina tradicional e popular (etnobotânica) e investigação farmacológica de extratos e dos constituintes químicos isolados (farmacologia).

As sociedades tradicionais têm sido, de alguma forma, influenciada pela medicina tradicional. No entanto algumas doenças podem ser vistas como sendo curáveis tanto por médicos quanto por outros especialistas, como por exemplo, benzedeiras ou pajés, sendo que o paciente doente pode aceitar a explicação da medicina ortodoxa e dos especialistas culturalmente mais próximos, seguindo as prescrições de ambos.

Estudos de etnobotânica se fazem extremamente necessários, uma vez que este pode ser o precursor de agentes importantes para a terapia de uma série de enfermidade, além do que esta modalidade de estudo pode contribuir em planos de conservação, resgate da cultura e fortalecimento de atos religiosos.

\section{Referências}

ALBUQUERQUE, U. P. de. A Etnobotânica no Nordeste Brasileiro. In: CAVALCANTI, T. B., (Org.). Tópicos atuais em botânica: Palestras convidadas do $51^{\circ}$ Congresso Nacional de Botânica. Brasília: Embrapa, p.241-249. 2000.

ALBUQUERQUE, U. P. de. The use of medicinal plants by the cultural descendants of African people in Brazil. Acta Farmaceutica. Bonaerense, v. 20, p.139-144, 2001

ALBUQUERQUE, U. P. Introdução à Etnobotânica. Recife: Bagaço, 87p. , 2002

ALBUQUERQUE, U. P.; LUCENA, R. F. P. (Org.). Métodos e técnicas na pesquisa etnobotânica. NUPEEA/Livro Rápido, 2004.

ALBUQUERQUE UP. Introdução à etnobotânica. 2.ed. Rio de Janeiro: Editora Interciência. 2005.

BEGOSSI, A.; LEITÃO FILHO, H.F.; RICHERSON, P.J. Plant uses in a brazilian coastal fishing community (Buzios Island). Journal of Ethnobiology, v.13, n.2,:p,233-256. 1993.

BETTEGA, P. V. C.; CZLUSNIAK, G. R.; PIVA, R.; NAMBA, E. L.; RIBAS, C. R.; GRÉGIO, A. M. T.; ROSA, E. A. R. Fitoterapia: dos canteiros ao balcão da farmácia. Archives of Oral Research, v.7, n.1, p 89-97, 2011.

BRUNETON, J. Pharmacognisie, phytochimie, plantes médicinales. 2 ed. Paris: Lavosier, 1993.

CAMARGO, M. T. L. Plantas medicinais e de rituais afro-brasileiros II. São Paulo: Ícone; 1998.

CAVALCANTE, P. B.; FRIKEL, P. A farmacopéia Tiriyó: estudo etno-Botânico. Belém, Museu Paraense Emílio Goeldi, 1973. 145p. (MPEG. Publicações Avulsas, 024).

COUTINHO, D. F.; TRAVASSOS, L. M. A.; AMARAL, F. M. M. do. Estudo etnobotânico de plantas medicinais utilizados por comunidades indígenas no estado do Maranhão - Brasil: Visão Acadêmica, Curitiba, v.3, n.1, p.7-12, 2002.

FERNANDES, V. Guia básico de plantas medicinais. Rio de Janeiro: Instituto de Estudos da Amazônia, 80p.1982.

FRIENDMAN, J.; YANIV, Z.; DAFNI, A.; PALEWITCH, D. A preliminary classification of the healing potential of medicinal plants, based on a rational analysis of an ethnopharmacological field survey among bedouins in the negev desert, Israel. Journal of Ethnopharmacology, v.16, p.275-287, 1986.

MACIEL, M. A. M. et al. Plantas medicinais: a necessidade de estudos multidisciplinares. Química Nova [online], v.25, n.3, p. 429-438, 2002.

MING, L. C. Levantamento de plantas medicinais na Reserva Extrativista "Chico Mendes"- ACRE. [Tese de doutorado apresentada ao Instituto de Biociências da Universidade Estadual Paulista "Júlio Mesquita Filho"- Campus Botucatu]; 1995.

MOERMAN, D. E.; ESTABROOK, G. F. Native Americans' choice of species for medicinal use is dependent on plant family: confirmation with metasignificance analysis. Journal of Ethnopharmacology, v.87, p. 51-59, 2003.

MORAIS, S. M. de; DANTAS, J. D. P.; SILVA, A. R. A.; MAGALHÃES, E. F. Plantas medicinais usadas pelos índios Tapebas do Ceará. Revista Brasileira de Farmacognosia, v.15, n. 2, p. 169-177, . 2005.

MUNANGA, K. Origem e histórico do quilombo na África. Dossiê Povo Negro - 300 anos. Revista USP, v. 28, p. 56-63, 1996

NASCIMENTO, A.P.B. Sobrepeso e obesidade: dieta, uso de recursos e adaptabilidade em populações 
humanas rural e urbana de Piracicaba, SP. 81p. [Tese de DOUTORADO - Escola Superior de Agricultura Luiz de Queiroz- ESALQ/USP], 2008.

NODORI, R. O; GUERRA, M. P. Biodiversidade: aspectos biológicos, geográficos, legais e éticos. p. 11-24. In: C.M.O. SIMÕES et al. (eds.). Farmacognosia da planta ao medicamento. Porto Alegre, Editoras UFRGS/ UFSC. 1999.

PHILLIPS, O.; GENTRY, A. M. The useful plants of Tambopata, Peru. I. Statistical hypothesis with a new quantitative technique. Economic Botany, v.47, n.1, p.1532, 1993.

POSEY, D. A. Etnobiologia: teoria e pratica. In: RIBEIRO, B. (org.). Suma etnológica brasileira etnobiologia. Rio de Janeiro: vozes, 1987.

PRANCE, G. T. What is etnobotany today ? Journal of Etnopharmacology, v.32, p.209-216, 1991.

RITTER, M. R.; SOBIERAJSKI, G. R.; SCHENKEL, E. P.; MENTZ, L. A. Plantas usadas como medicinais no município de Ipê, RS, Brasil : Revista Brasileira de Farmacognosia, v 12 n. 2, p 51-62, 2002.

RAO, R. R, HAJRA, P. K. Methods of research in ethnobotany. In: JAIN, S. K. (ed.). A manual of ethnobotany. Jodhpur: Rajasthan Law Weekly Press; p. 33-41, 1987.

RATES, S. M. K.; SANTOS, L. S. Piper methysticum. Um novo ansiolítico? Revista Brasileira de Farmácia, v. 2, n. 78, p. 44-48, 1997.

RODRIGUES, E. Usos rituais de plantas que indicam ações sobre o Sistema Nervoso Central pelos índios Krahô, com ênfase nas psicoativas. [Tese de doutorado apresentada ao Depto. de Psicobiologia da Universidade Federal de São Paulo - Escola Paulista de Medicina]; 2001.

SHERWOOD, R. M. Propriedade intelectual e desenvolvimento econômico. Trad. Heloísa de Arruda Villela. São Paulo: EDUSP,. 215 p. 1992

VEIGA-JUNIOR, V. F. Estudo do consumo de plantas medicinais na Região Centro-Norte do Estado do Rio de Janeiro: aceitação pelos profissionais de saúde e modo de uso pela população. Revista Brasileira de Farmacognosia, v.18, p.308-313, 2008.

ZUCOLOTTO, T.; APEL, M.; RATES, S. M. K. Análise de produtos fitoterápicos comercializados em Porto Alegre, RS. Revista do Instituto Adolfo Lutz, v. $58, \quad \mathrm{n} \quad 2, \quad$ p. 25-31, 1999. 